\title{
Kenya's Response to COVID 19, a Descriptive Review
}

\author{
Peter S. Ongwae ${ }^{1} \&$ Kennedy M. Ongwae ${ }^{2}$ \\ ${ }^{1}$ Bpharm MPH., The Director Hillside Pharmacy Limited, Chairman Modify Lifestyle Initiatives (MLI), Webuye, \\ Kenya \\ ${ }^{2} \mathrm{MBchB}, \mathrm{MPH}, \mathrm{PhD}$. Public Policy and Administration Expert, Kenya \\ Correspondence: Peter S. Ongwae, Hillside Pharmacy Limited, PO Box 1397, Webuye 50205, Kenya. E-mail: \\ dr.peterongwae@gmail.com
}

Received: June 12, 2020 Accepted: June 25, 2020 Online Published: July 6, 2020

doi:10.5539/gjhs.v12n9p69 URL: https://doi.org/10.5539/gjhs.v12n9p69

\begin{abstract}
Coronavirus Disease 2019 (COVID-19) is a respiratory viral infection caused by Severe Acute Respiratory Syndrome Corona Virus 2. The first case of the infection was confirmed in Wuhan China in 2019, by early March 2020 the infection had spread to all the continents of the World attaining a pandemic status as declared by the World Health Organization on $11^{\text {th }}$ March 2020. Kenya reported its first confirmed COVID-19 case on $13^{\text {th }}$ March 2020 , increasing to 5206 cases as reported on $24^{\text {th }}$ June 2020. COVID-19 is a novel infection with no known cure, currently, the mainstay to the infection is through public health measures. These measures are hand hygiene, cough etiquette, face masking and social distancing among others. This review aims to examine the literature on the public health measures which have been used to control outbreaks caused by respiratory viruses. The review will also identify the public health measures which Kenya is using to control the pandemic. A descriptive survey on the confirmed COVID-19 cases in Kenya shows that infection is on the rise and the epidemic curve is on the ascending trajectory. The review informs that the country requires a high level of preparedness to handle COVID-19. The areas to consider include, having robust health care systems with an adequate number of; hospital beds, healthcare workers and personal protective equipment.
\end{abstract}

Keywords: cough etiquette, face masks, hand washing, social distancing

\section{Background}

Coronavirus Disease 2019 (COVID-19) is a viral disease caused by Severe Acute Respiratory Syndrome Corona Virus 2 (SARS-CoV-2). The disease started in Wuhan in the Hubei province of China in 2019 and was declared a pandemic by World Health Organization (WHO) on 11th March2020 (WHO 2020). The disease has spread to all continents affecting 213 countries by 28th May 2020 with 5825342 confirmed cases and a death toll of 358235 (WHO 2020) Kenya is among the countries with confirmed COVID-19 cases and deaths. The first case was confirmed on 13th March 2020 and the first death was reported on 26th March 2020. By 28th May 2020, Kenya had 1618 confirmed cases and 58 deaths (MOH, News 2020). At the early stages of the outbreak of COVID-19 the response strategies were mainly based on trial and error partly because the infection is novel. There was also insufficient data available due to insufficient information sharing and blame games among countries and leading health organizations. The global community lost the opportunity of deploying effective public health measures of containing the SARS-CoV-2 spread at the onset. While further evidence evolves on the novel COVID-19, it has become increasingly clear that measures that support public health preparedness and planning can minimize the spread (ECDC 2020). These measures include hand washing with soap and running water which according to United Nations Children's Fund (UNICEF) when done correctly is critical against the novel SARS-CoV-2, with its latest data showing that three out of five people worldwide have basic hand washing facilities (UNICEF 2020). As COVID-19 continues to spread UNICEF reminds the public of the importance of hand washing as key intervention, prevention measure against the pandemic, further indicating that hand washing with soap is one of the cheapest, most effective interventions to protect against the coronavirus (UNICEF 2020). Speaking to Medscape Elizabeth Scott a co-director of the centre for hygiene and health in Home and Community at Simmons University in Boston says that hands are the connecting piece, one cannot necessarily control what to touch, or who else touched it, but hand washing looks after the hands. Hand washing with soap and water she says is a powerful weapon against germs including SARS-CoV-2. This is because soap removes things and contaminants from the hands, at the same time it busts open the virus breaking it apart since the coronaviruses are encased in a lipid envelope, hence 
denaturing the virus. Further soap acts mechanically, making the skin slippery, so with enough rubbing the coronaviruses can be pried off and rinsed away.

Alcohol-based hand sanitizers may also be used, but provide limited added benefit over soap and water in the community setting and if used should contain $60-85 \%$ alcohol. According to the Centre for Disease Control and Prevention (CDC), if hands are soiled, soap and water should precede the use of alcohol-based hand sanitizers. During the COVID-19 pandemic CDC advises that hands should be kept clean. CDC outlines the right way to wash hands with soap by following five steps which are; wet the hands, lather the hands, scrub the hands for at least 20 seconds, rinse the hands and dry the hands. The recommendation is that this should be done regularly throughout the day.

Cough etiquette refers to covering mouth and nose when coughing and sneezing using a tissue or cloth handkerchief to reduce the person to person transmission through droplet which is a known mode of transmission of COVID-19 or coughing and sneezing into the flexed elbow. It is important that tissues are properly disposed immediately after use into a closed bin and the hands are washed with soap and water (WHO 2020).

COVID-19 pandemic is an emerging, rapidly evolving situation affecting countries all over the world. There are current scientific uncertainties about the virus, with the possibility of aerosol viral transmission. Therefore aerosolization could be considered a third potential route of transmission along with large droplets emitted from sneezing or coughing and the transfer of viral particles after touching a contaminated surface. CDC recommends everyone can do their part by wearing a cloth face covering which is meant to protect other people in case one is infected. WHO recommends, mass use of face covering, with CDC advising on wearing of cloth mask in public to limit aerosol transmission. Many other countries including Canada, South Korea, Chez Republic and Kenya among others have supported mass masking during this pandemic.

There is limited available evidence on the effectiveness of environmental measures in curbing the impact of respiratory virus pandemics. These measures may reduce viral transmission and should be used at all times and in all settings during the containment and mitigation phase of the COVID- 19pandemic. Such measures include; routine cleaning and disinfection of frequently used surfaces and objects like phones, laptops, tablets, doorknobs, toilets and keyboards) with water, detergents and disinfectants. Washing laundry at warmest temperatures and airing it in the hot sun for at least five hours (ECDC 2020). Minimal sharing of objects, (such as drinking glasses, eating utensils, writing pens, towels and bed linen). Allow for air ventilation in rooms where people gather regularly by opening windows, and whenever possible hold events in the open air with social distancing (ECDC 2020)

Social distancing refers to efforts that aim to decrease or interrupt transmission of COVID-19 in a population subgroup or group by minimizing physical contact between potentially infected, asymptomatic or pre-symptomatic individuals and healthy individuals or between population groups with a high rate of transmission and population groups with no or low level of transmission. These measures are meant to ensure that there is low transmission among the communities and thereby reducing pressure on health services. Social distancing measures can be implemented concomitantly with containment efforts such as quarantine, self-isolation, self-monitoring and contact tracing (ECDC 2020).

On individual social distancing, the measures are; first, isolation of cases confirmed or suspected and can be voluntary or mandatory. Second, quarantine of contacts, these are health persons who may have had a high or low risk of exposure to contact of COVID-19 case, quarantine can be voluntary or mandatory. And third, stay at home recommendations are issued to the public to avoid mass gatherings and close contacts with people especially known high-risk groups (ECDC 2020).

Multiple-person social distancing measures involve; First closure of educational institutions including pre-primary, primary, secondary schools, and higher learning institutions such as universities, colleges and research institutes. Second, workplace closures, these include the closure of offices factories, retail shops, restaurants, cafe, bars and sports clubs. This can be adjusted to include flexible working schedules/shifts, encouraging physical distancing measures within workplaces, opportunities for distance working/teleworking, increased use of email and teleconferences to reduce close contact. Third, measures for special populations limiting outside visitors and also limiting contact between inmates/ patients in confined settings such as care facilities for the elderly, psychiatric institutions, prisons and homeless shelters. Fourth, cancellations of mass gathering affecting cultural events, sporting events (Football indoor and outdoor athletic games, marathon races etc) festivals, faith-based event (such as Sabbath gathering and camps), conferences (Scientific conferences, meetings and trade fairs). Fifth, cordon/mandatory quarantine of building or residential area, or county. These refer to quarantine or closing off of a designated area (city, county or region) or having a lockdown for the entire population in a jurisdiction or 
minimizing hours of movement within the day using a curfew (ECDC 2020).

Further measures include International travel advice where government advises against travel during a pandemic. It aims to reduce the number of people who are infected during a trip to areas where community transmission is ongoing, reduce importation of infected people from abroad and reduce transmission among travelers (ECDC 2020)

Screening at the entry point s such as national borders, airports, seaports and other places where travelers may enter a country. Screening is done using non- contact, infrared thermometers. The process involves sharing information on infection and advice on how to seek medical assistance should symptoms develop, and how to reduce the risk of infecting others ECDC 2020).

Also, broad domestic travel restrictions may have an impact in delaying a pandemic, especially if implemented at the early stages of the pandemic. These restrictions are considered during the containment phase of a pandemic of high severity. Such restrictions may be applied to an isolated setting such as counties or metropolitans (ECDC 2020).

Governments can order border closures during a pandemic. The closure aims to reduce the risk of importation of the infection from countries which will be experiencing high transmission through travel restrictions to and from affected areas (ECDC 2020).

\section{Kenya's Implementation, of the Measures to Prevent COVID-19}

These measures were triggered by the discovery of the first case of COVID 19 in Kenya on $13^{\text {th }}$ March 2020. The measures were announced by the president of the Republic of Kenya Uhuru Kenyatta on $15^{\text {th }}$ March 2020.

The measures implemented immediately were as follows:

Hand hygiene thorough washing of hands with soap and running water or hand sanitizing with alcohol-based hand sanitizer, cough etiquette which involved covering mouth and nose with a tissue or into a flexed elbow while coughing. To promote hand washing and cough etiquette the Kenyan Government through the Ministry of Health $(\mathrm{MOH})$ disseminates target a message widely through social media and mass media which ensure that Kenyans are getting informed (MOH News 2020). This is to assist Kenyans in making the correct decisions on COVID-19 prevention measures.

This was further reinforced with a public health subsidiary legislation, dated $6^{\text {th }}$ April 2020, which additionally stipulated that all persons wear a face-covering / clothe/ shield or mask covering mouth and nose while in public places or spaces (MOH News 2020).

Environmental measures were put in places which require regular cleaning and disinfection of public facilities such as hospitals, shopping malls and other shopping points. Also, disinfection of all cargo vessels, aircraft or ships that come into the country at the point of departure or arrival was ordered (MOH News 2020).

International travel measures were too introduced whereby travel from any country with any COVID-19 is restricted. Kenyan citizen travelling back and those foreigners with valid permits will be allowed into the country but to observe strict self-quarantine for 14days at home or a government-designated facility MOH News 2020).

Further multiple-person social distancing was introduced, these involved closure of all schools and higher learning institutions by Friday $20^{\text {th }}$ March 2020 partial closure of government and private offices allowing for people to work from home with effect from $15^{\text {th }}$ March 2020 (MOH News 2020).

On noticing that there was a steady rise on confirmed COVID-19 cases, the Government of the Republic of Kenya announced a 7.00 PM to 5.00 AM curfew with effect from $25^{\text {th }}$ March 2020 to be observed throughout the republic for a period of 21 days $^{3}$. This has since been extended twice. As regarding travel-related measure the Cabinet Secretary (CS), Health banned all flights into Kenya effective $25^{\text {th }}$ March 2020 (MOH News 2020).

On domestic travel restriction, the President of the Republic of Kenya announced the cessation of movement in and out of the Nairobi metropolitan area, Mombasa, Kilifi and Kwale effective $6^{\text {th }}$ April 2020 for a period of 21 days with an extension of a similar period (MOH News 2020).

On $7^{\text {th }}$ May 2020, the CS health declared a lockdown on Eastleigh in Nairobi and old Town in Mombasa for a period of 14days with an extension of similar period(MOH News 2020).

\section{Methodology}

3.1 Study Design

Descriptive cross sectional. 


\subsection{Study Population}

Initially the tests were done on samples collected from individuals who had recently travelled into the country and had been quarantined including their contacts. This is after their countries of origin reported COVID-19 outbreak. Gradually this has been expanded to testing special groups such as those who live in densely populated areas, correctional facilities, army barracks, police stations, health workers and also inter country long distance drivers.

\subsection{Data Collection}

The data was retrieved from the MOH News portal which has information on the daily confirmed COVID-19 cases, the sampled population and major announcements concerning the pandemic. The data for this review was collected retrospectively.

\subsection{Data Analysis}

Descriptive statistics was used to analyze the data.

\section{Results}

The data and the analysis for percentage and mean are detailed on Table 1.

The epidemic curve is shown in Figure 1.

Table 1. Descriptive Survey on Kenya's COVID-19 confirmed cases. Data publicly available on MOH News 2020

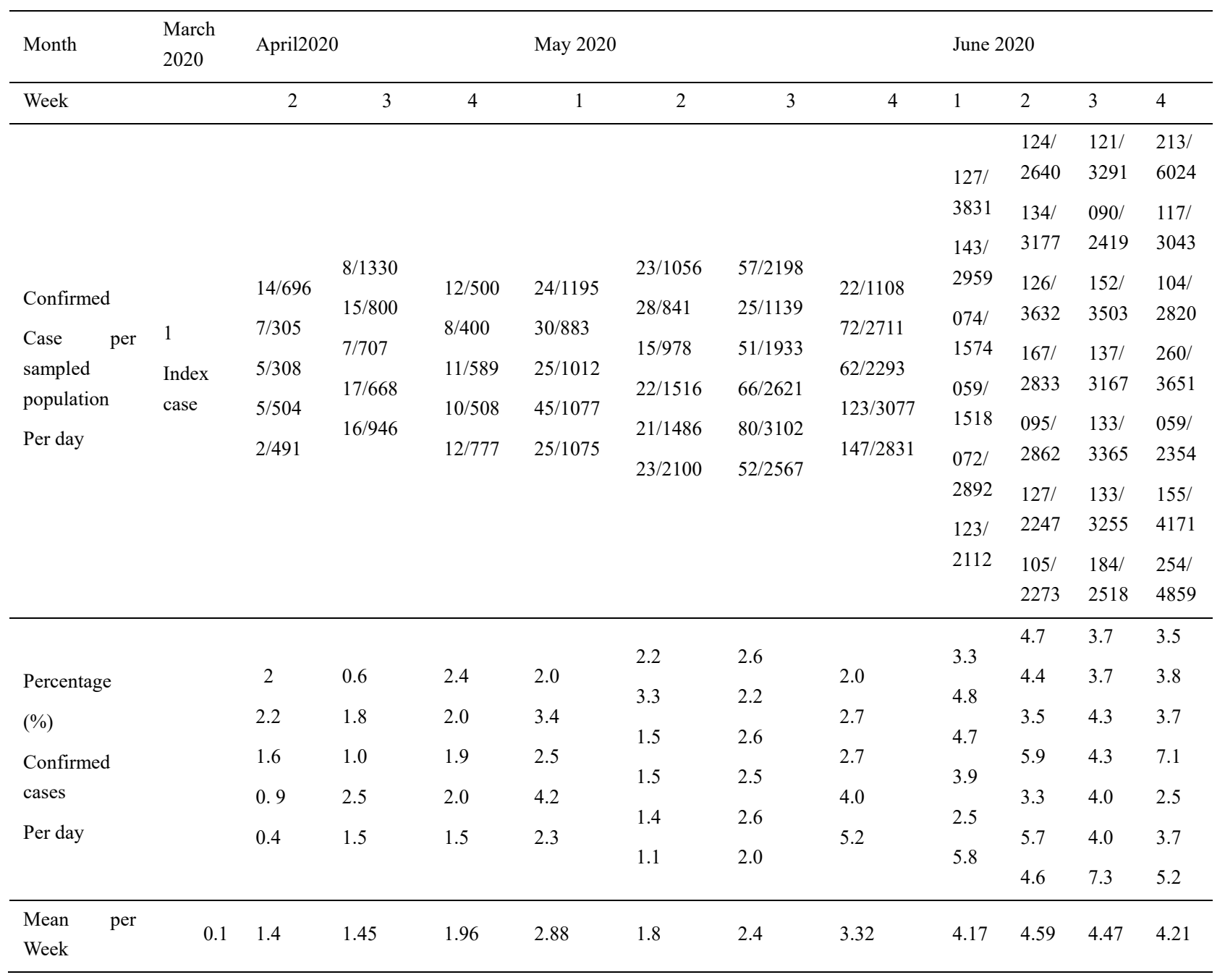




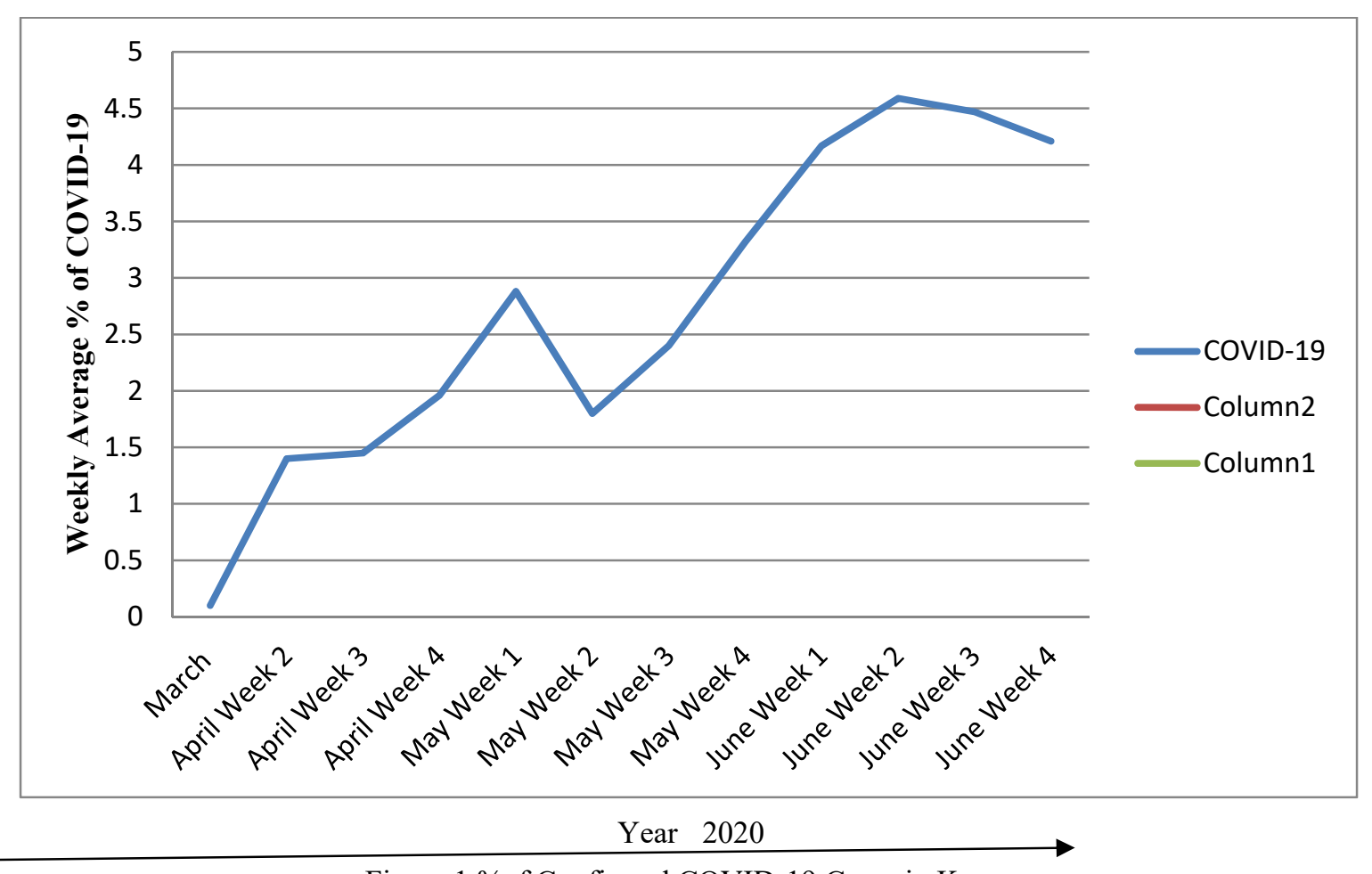

Figure 1.\%of Confirmed COVID-19 Cases in Kenya

At the early stages of the pandemic, the confirmed COVID-19 cases were travelers from abroad or their immediate contacts. As the epidemic has progressed it has emerged that the cases confirmed have no history of foreign travel or contact, therefore the epidemic is a community spread outbreak through the local transmission. Furthermore, some of the confirmed cases are asymptomatic, these worsen the infection spread as they are difficult to identify. This too is worrying to the surveillance teams because it means that the SARS-CoV-2 is moving undetected through the population.

\section{Discussion}

Hand washing among the Kenyan communities is a basic hygiene measure practiced religiously before a meal is shared. It is now prescribed as a public health measure to combat COVID-19 after hand washing the public will jokingly ask for a meal. That tells us that this measure has been adopted by Kenyans who are now hand washing regularly at various private and public places which include their homes, service centers such as pharmacy, hospitals, supermarkets, banks and shops. Hand washing with soap and water is cost-effective, less prone to stocks outs and price like, properly done this measure is helping prevent the proliferation of COVID-19 and would also prevent the transmission of other communicable diseases

Implementation of environmental measures during the COVID-19 pandemic may not be easy to reinforce to the masses. However, with the help of health education on the importance cleaning and disinfecting common surfaces, avoiding sharing of objects and the need to allow for ventilation individuals can be encouraged to apply these measures. Public and private institutions adopted these measures into their routine protocols, this is to ensure that both their workers and customers are safe.

Social distancing measures have been implemented to varying degrees, public passenger vehicles are carrying one-third of capacity, and further service centers such as banks, supermarkets, fuel stations are requesting that customers keep a one-meter distance from each other as they queue for service. This is augmented by the requirement that all persons wear a face covering while in public places. These measures have to some reasonable extent been effective in controlling the spread of COVID-19. We note here that there are situations where physical distancing measures are violated, however, this occurs in open-air spaces where the risk of COVID-19transmission is low.

Quarantine of persons as a measure to prevent COVID-19 has had its fair share of challenges. At one-time government banished curfew violators into quarantine for 2 weeks. That flip side of quarantine has increasingly made it unpopular as it is unfriendly. Adherence to quarantine has been known to vary during infectious disease 
outbreaks. There has to be a clear rationale for quarantine and information about its protocols. There is a need to emphasis on the benefits of engaging in quarantine to self, family and community. Equally important is to ensure that the quarantine facilities meet the minimum requirements with sufficient supplies of food, medication and other essential supplies.

The multi-person social distancing of closing schools, colleges and higher learning institution with further banning of congregational meetings such as churches and sports was immediately implemented and has been enforced by the government. This measure has been effective in controlling the spread of COVID-19.

Equally, the night curfew which has been observed throughout the Republic of Kenya running daily for ten hours is what we can regard as a masterstroke measure of the COVID-19 prevention in Kenya. This is because with a night curfew all measure of social distancing are inadvertently activated ensuring that the spread of COVID-19 is limited.

The banning of all air flights into Kenya and entry through seaports has ensured that there is no new importation of COVID-19 into the country.

\section{Conclusion}

The epidemic curve is on the ascending trajectory with no sign of flattening. Therefore, there is urgency for the Government of the Republic of Kenya to continue testing for COVID-19 and also tracking and tracing. The entire population should be instructed to continue with the new normal of hand hygiene, social distancing, and mass masking. There will need to identify ground zero epicenters, in facilities such as prisons, care homes or within pockets of groups within the population. The Government will need to formulate clear policies to allow for isolation of those with symptoms and reduce visits to such areas.

Both national and county governments should work toward robust healthcare systems with adequate number of, hospital beds, health workers, and personal protective equipment. This is to prepare both national hospitals and county hospitals for a surge in case the prevention measures fail to hold. This will ensure that the hospitals are in a state whereby they will not be overwhelmed with COVID-19 patients. Delaying COVID-19 infections will also allow time for research on possible therapies and vaccines for the infection.

Efforts should be put in place to counter COVID-19 stigma so that patients needing care in hospitals do not shy away.

Telemedicine to be introduced as this will enhance social distancing and ensure continuity of care. This is especially crucial for those persons with elevated risks and vulnerabilities.

\section{Competing Interests Statement}

The Authors declare no competing interest.

\section{References}

CDC. http://www.cdc.gov/handwashing Retrieved 20th May 2020

ECDC.(2020). Imperial college COVID-19 modeling 16.3.2020.https://doi.org/10.25561/77482

Medscape journal. Retrieved March 06, 2020, from https://www.mediscape.com

MOH News.Retrieved June 24, 2020, from https://www.health,go.ke/category/news

UNICEF. Retrieved May 20th, 2020, ftom http://www.unicef.org

WHO: Coronavirus disease 2019 (COVID-19) situation reports. Retrieved 28th May 2020, from https://www.who.int/emergencies/diseases/novel-coronavirus-2019/situation-reports

WHO: Director-General's opening remarks at the media briefing on COVID-19-11. Retrieved Retrieved 28th May, 2020, from https:/www.who.int/dg/speeches/detail/who-director-general-s-opening-remarks-at-the-mediabriefing-on-covid-19---11-march-2020

WHO.

Retrieved

from https://www.who.int/emergencies/diseases/novel-coronavirus-2019/technical-guidance/infection-prevention -and-control

Webster, R. K., Brook, S. K., Smith, L. E., Woodland, W. S., \& Rubin, S. J. (2020). How to improve adherence with quarantine. Rapid review evidence Public Health Journal, (182), 163-169. https://doi.org/10.1016/j.puhe.2020.03.007 


\section{Copyrights}

Copyright for this article is retained by the author(s), with first publication rights granted to the journal.

This is an open-access article distributed under the terms and conditions of the Creative Commons Attribution license (http://creativecommons.org/licenses/by/4.0/). 